\title{
The Packaging Design Approach and Evaluation Process by Integrating ISO/TR 14062 in a Decision Support Methodology
}

\author{
Athakorn Kengpol* \\ AIEMSRC,Department of Industrial Engineering, Faculty of Engineering, KMUTNB, Bangkok, Thailand \\ Jeeranuch Buddeejeen \\ AIEMSRC,Department of Industrial Engineering, Faculty of Engineering, KMUTNB, Bangkok, Thailand
}

\author{
Markku Tuominen \\ Department of Industrial Engineering and Management, Lappeenranta University of Technology, Finland \\ * Corresponding author. E-mail: athakorn@kmutnb.ac.th
}

Received: 5 February 2014; Accepted: 3 March 2014; Published online: 25 April 2014

DOI: $10.14416 / j$. .ijast.2014.03.001

\begin{abstract}
The environmental, economic and social conscious are particularly important in the sustainable design product. ISO/TR 14062 suggests the conceptual guideline in environmental management into product and packaging design and development stage. However, the evaluation of the sustainable design selection based upon life cycle thinking is unavailable in detail design process. The objectives of this research are to develop the sustainable packaging methodology at the conceptual design phase, and to enhance the new guidelines to quantify an efficient sustainable packaging evaluation process by integrating ISO/TR 14062 in a decision support methodology. It is intended to integrate between life cycle thinking and major stakeholders for functional quality, cost, and environmental aspects in the early design phases. The methodology has been tested with a very large enterprise in the section of hard disk drive internal factory packaging and it was found that the approach of a new packaging design can assist the designer to develop the sustainable packaging whilst achieving desirable functions, increasing environmental conscious and cost effectiveness. In addition, the evaluation process can assess decision scenarios on the new design according to the investment comparison.
\end{abstract}

Keywords: ISO/TR 14062, Sustainable packaging, Decision support methodology, Life cycle thinking

\section{Introduction}

As international commerce, internet sales, and the trend toward products with short life-spans continue to develop, the volume of goods placed on the market and subsequent waste from these products and their packaging have been increased dramatically, often faster than waste disposal capacity [1]. Packaging waste is increased by $40 \%$ in Organization for Economic Co-operation and Development (OECD) countries [2]. These effects have generated a push towards reducing and recycling packaging and waste disposal solutions come at a price, and someone has to pay. Many countries including some US States, Canada, Western and Eastern Europe, South Africa,
Australia, Brazil, China, Japan, Taiwan, Tunisia, and South Korea have implemented environmental packaging requirements to allocate and distribute waste management costs, shift responsibility onto the Extended Producer Responsibility (EPR), and to decrease the environmental impact of product and packaging system [3]. This trend reinforces the consciousness of environmental responsibility of competitive companies, industries and global business.

Environmental, Economic and social conscious design called sustainable design, is particularly important in the manufacturing industries, and many design methods and tools have been developed to support sustainable design. In order to design sustainable packaging, it is crucial to take environmental 
aspects into account in the early design phase, such as the conceptual design phase [4]. Because packaging design is a critical determinant of a manufacturer's competitiveness. It has been claimed that as much as $80 \%$ of the costs of packaging development, manufacture and use are determined during the initial design stages [5]. The earlier in the design phase life cycle that a design team considers environmental factors, the greater the potential for environmental benefit and cost reduction [3]. According to ISO/ TR 14062 [6], there is a guideline for environmental managements into product and packaging design for industrial standardisation at conceptual design phase. However, the methodology for delivering sustainable design prototypes based upon life cycle thinking stages are unavailable and no evidence has been found on the suggestion on sustainable cost effects and design evaluations.

The objectives of this research are to develop sustainable packaging design methodology at the conceptual design phase, and to enhance the new guidelines to quantify efficient to life cycle evaluation process. This paper contains an approach for the increasing of environmental consciousness in packaging design main concepts, which is the systematic integration of environmental considerations into packaging and process design. It is encompassed by the sustainable packaging design approach and evaluation process concept, which have been developed. This paper proposes an approach to qualify the conceptual sustainable packaging design phase and evaluate the packaging process design systematically. The conceptual is presented in Figure 1,

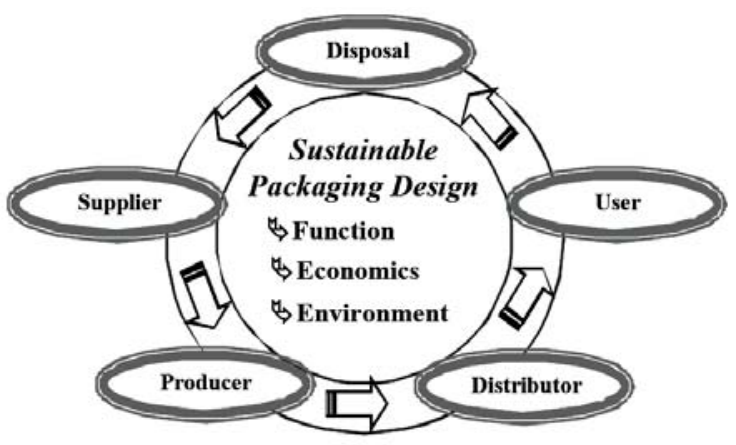

Figure 1: Sustainable packaging design concept.

this conceptual is an integrated function, economics and environmentally conscious in packaging stakeholders leading to sustainable design and development by using the life cycle thinking [7].

\section{Methodology}

ISO/TR 14062 [6] is the core concept of this approach that describes concepts and guideline practices relating to the integration of environmental aspects in packaging design and development. This concept is illustrated in Figure 1. The sequences of the major steps and appropriate techniques of the sustainable packaging design and process evaluation are illustrated in Figure 2 at the Packaging Design Process. The decision support tools, developed by the authors, are also illustrated in Figure 2 at Tools Sequence. The four steps show the sustainable packaging design process. The detail of application in each decision support tool is described in the case study section.

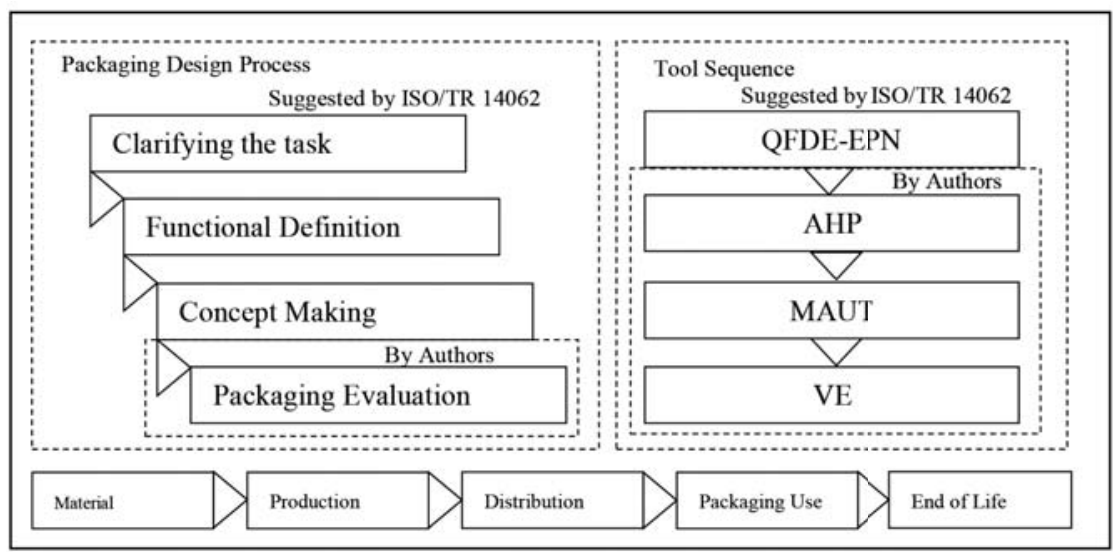

Figure 2: The approach of sustainable packaging design and process evaluation. 


\subsection{Clarifying the task}

ISO/TR 14062 [6] suggests Quality Function Deployment for Environment (QFDE) is used to analyse customer and environmental requirements. Gathering and analysing the voice of the customer is critically important to QFDE in order to provide customer oriented packaging. The voice of the current and environmental customer needs can come from a wide variety of sources such as surveys, focus groups, interviews, trade shows, complaints, and even expert opinions $[8,9]$. Later, customer needs should be translated into technical attributes. In reality, customer needs are fulfilled by completing those specified technical attributes. The QFDE is illustrated in Appendix A Table A1. The customer requirements are obtained from the Equation (1) - (4).

$A_{i}=\frac{\sum_{i=1}^{10}\left[i\left(X_{A i}\right)\right]}{n}, B_{i}=\frac{\sum_{i=1}^{5}\left[i\left(X_{B i}\right)\right]}{n}$,

$C_{i}=\frac{\sum_{i=1}^{5}\left[i\left(X_{C i}\right)\right]}{n}, D_{i}=\frac{\sum_{i=1}^{5}\left[i\left(X_{D i}\right)\right]}{n}$

$E_{i}=D_{i} / B_{i}$

$R W_{i}=A_{i} \times E_{i} \times F_{i}$

$p_{i}=R W_{i} / \sum_{i=1}^{I} R W_{i}$

The following Equation (1) - (4), $X_{i}$ is the numbers of customer at score $i, n$ is total customer numbers, $A_{i}$ is the importance to customer, $B_{i}$ is the customer satisfaction performance, $C_{i}$ is the competitive satisfaction performance, $D_{i}$ is the goal, $E_{i}$ is the improvement ratios, $F_{i}$ is the sale point ( $\mathrm{Strong}=1.50$, Medium $=1.20$, Weak $=1.0), R W_{i}$ is the raw weight, and $p_{i}$ is the normalised raw weight.

In reality, customer needs are fulfilled by completing those specified technical attribute. QFDE can be defined the stakeholder's needs and then, potential requirement approach use to clarify and prioritise the cause and effect analysis. Sheng and Jahau [10] use Environment Priority Number (EPN) to assign internal requirements (company impact), external requirements (customer impact) for packaging concepts making. Jaha and Wai [11] suggest environmental impact factor for sustainable packaging development based upon the potential severity of the environment issue. This method is ease of use and a powerful pro-active engineering quality method, has helped to clarify the current packaging, and can encounter weak points of packaging. In this research, we take the inside requirement with Company impact $\left(C_{i}\right)$, outside requirement with Market impact $\left(M_{i}\right)$ and responsibility requirement with Environmental impact $\left(E_{i}\right)$ into severity consideration. The raw environmental priority number $\left(E P N r_{i}\right)$ can determine the environmental priority of packaging that are obtained from the Eq. (5) - (7).

$$
\begin{aligned}
& r_{i}=\sum_{i=1}^{I} C_{i} M_{i} E_{i} \\
& E P N r_{i}=\sum_{i=1}^{I} p_{i} r_{i} \\
& E P N r n_{i}=E P N r_{i} / \sum_{i=1}^{I} E P N r_{i}
\end{aligned}
$$

The following; EPNrn $n_{i}$ is the raw normalised environmental priority number, $i=1, \ldots, I$ is the customer requirement, $p_{i}$ is normalised raw weight from QFDE is illustrated in Appendix A Table A1, and $r_{i}$ is relative priority number.

\subsection{Functional definition}

After the current packaging situation clarified the task and critical points to improvement based upon stakeholder requirements. The designers should be evaluated the requirements by using pair wised comparison criteria. Analytic Hierarchy Process (AHP) method applies at the conceptual analysis. AHP can help to bring a consistency ratio $(C R)$ by using pair wised comparison criteria [12]. In order to compare the selected design with the original design; a set of tools, cost analysis and AHP have been conducted to evaluate all the benchmarking parameters. The improved AHP method determines weights by pair wise comparison between each pair of criteria. Each comparison is transformed into numerical value on a scale as Appendix B Table B1.

The importance weighting value $\left(W_{i}\right)$ is obtained from the Equation (8) and random consistency ratio $(C R)$ is calculated from the Equation (9) and (10). 
The importance index $\left(r_{i}\right)$ be used to composed into a matrix $A=\left\{a_{i j}\right\}$, where

$A=\left[a_{i j}\right]_{m x m}, a_{i j}=\left\{\begin{array}{c}r_{i}-r_{j}+1, r_{i}>r_{j} \\ 1, r_{i}=r_{j} \\ {\left[\begin{array}{c}\left.r_{i}-r_{j}+1\right]^{-1}, r_{i}<r_{j}\end{array}\right.}\end{array}\right.$

$W_{i}=\frac{1}{n} \sum_{j=1}^{n} \frac{a_{i j}}{\sum_{k=1}^{n} a_{k j}}, i=1,2, \ldots, n$

First estimating the Consistency Index $(C I)$ in Equation (9)

$C I=\lambda_{\max }-n / n-1$

Then, the $C R$ in Equation (10) is the ratio of consistency ratio $(C I)$ to random index $(R I)$.

$C R=C I / R I$

Saaty [12] suggests Value of the Random Index $(R I)$ which is presented in Appendix B Table B2. If the random consistency ratio $(C R)$ is greater than 0.10 , the pair wise comparison result should be rejected. Another cycle of re-comparison for the importance weighting value $\left(W_{i}\right)$ of the criteria is required until $C R$ is falling below 0.10 .

\subsection{Concept making}

Afterward the designers should be specified the packaging function by using AHP technique to pair wise criteria comparison. From this point, several packaging prototypes can be developed from this straight point. Then, they need to brainstorm, discuss, and analyse pros and cons each of proposed packaging prototype options based upon optimising functional structure. The Multi-Attribute Utility Theory (MAUT), which is well known in consumer organisations for engineering parameter evaluations, can be applied. In the multi-attribute utility analysis, decision support systems play important roles and they have been utilised as an integral part of effective and efficient analysis because, even in identifying a single-attribute utility function and trade-off analysis between a pair of attributes [13]. It is important that engineers make logical and well-reasoned decisions. The decision process can prove to be quite complicated, especially when a trade off needs to be made. The purpose for using Multi-Attribute Utility Theory in decision-making is to create a mathematical model to aid the process. It gives the decision maker the ability to quantify the desirability of certain alternatives. The result of using this method is a function, which represents the designer's preferences, given a certain set of design attributes. Where $u_{i}$ is unify dimensional utility function of the $i$ attribute, $\lambda_{i}$ is the weights of importance, $k$ is the scaling alternative, $\underline{B}^{k}$ is lower bound attribute, $\bar{B}^{k}$ is upper bound attribute as the Equation (11) - (16).

$u(x)=\lambda_{1} u_{1}\left(x_{1}\right)+\ldots+\lambda_{n} u_{n}\left(x_{n}\right)=\sum_{i=1}^{n} \lambda_{A} u_{i}\left(x_{i}\right)$

$u_{i}\left(x_{i}^{*}\right)=1, u_{i}\left(x_{i}^{0}\right) \quad=0$

$\sum_{i=1}^{n} \lambda_{i}=1, \lambda_{i} \quad \geq 0$

$\underline{u}_{i}\left(x_{i}^{k}\right)=1$ if $x_{i}^{k} \quad=x_{i}^{*}$,

$\underline{u}_{i}\left(x_{i}^{k}\right)=0$ Other cases

$\bar{u}_{1}\left(x_{i}^{k}\right)=0$ if $x_{i}^{k} \quad=\quad x_{i}^{0}$,

$\bar{u}_{1}\left(x_{i}^{k}\right)=1$ Other cases

$\underline{B}_{k}=\sum_{i=1}^{n} \lambda_{i} \underline{u}_{i}\left(x_{i}^{k}\right), \bar{B}^{k}=\sum_{i=1}^{n} \lambda_{i} \bar{u}_{i}\left(x_{i}^{k}\right)$

\subsection{Packaging evaluation}

The final step is evaluating the value of packaging design concept with comparison the functional utility with life cycle cost of packaging prototype's development. Value Engineering (VE) is a systematic method to evaluate and examine the value and VE is the ratio of function to cost. Chan and Ip [14] suggest that the value of customer satisfaction can be predictable in stage of new product development in terms of idea generation and product improvement. VE can assist firms to designing, developing new products that are market driven based upon functional utility requirements and sustain business growth, and profitability through the life cycle cost selection. VE is applied to become Sustainable Packaging Value (SPV) as Equation (17). 
$S P V=F U / L C C$

Where, $F U$ is the Functional Utility, $L C C$ is the life cycle cost.

\section{Case Study Result}

Hard Disk Drive (HDD) is highly growth in the sales of data storage of information technology enterprise. Hard Disk Drive (HDD) is one of the most sensitive products to handling and transportation at a shock factor level less than 25G shock level [15]. It also requires good protective packaging to keep its quality during the manufacturing process and transportation. The trend of the new technology also requires a smaller and lower weight hard disk drive whilst with larger capacity. If that packaging is better than necessary or it is an over packaging, the company could lose money. Moreover, packaging disposals require more budgets to sanitise environment and social management [16]. That is why this research proposes a way to develop a systematic, sustainable and sustainable in-house packaging design using for 2.5", 3.5" inside the company, which focuses on the conceptual design phase. This paper contains an approach for the increasing of environmental consciousness in packaging design main concepts; the systematic integration of environmental considerations into packaging and process design. The advantage of the design concept development can help packaging engineers step by step and can perform cost saving in manufacturing and in-house packaging.

\subsection{Clarifying the task}

At this stage, the specified packaging requirements in life cycle phase are developed from brainstorming of major stakeholders (Supplier, Manufacturer and Packer, Distributor, End User, and Disposal). The design team analysis the existing HDD internal factory packaging and prioritise the weighting score $\left(p_{i}\right)$ from the each requirement. In Appendix A Table A1 is shown that the $p_{i}$ score is calculated according to Equation (1) - (4). After understanding the priority of requirements, the designers can consider the internal (company impact: $C_{i}$ ) and the external factors (market impact: $M_{i}$ and environmental impact: $\left.E_{i}\right)$ from the each requirement as in Table 1. The Raw

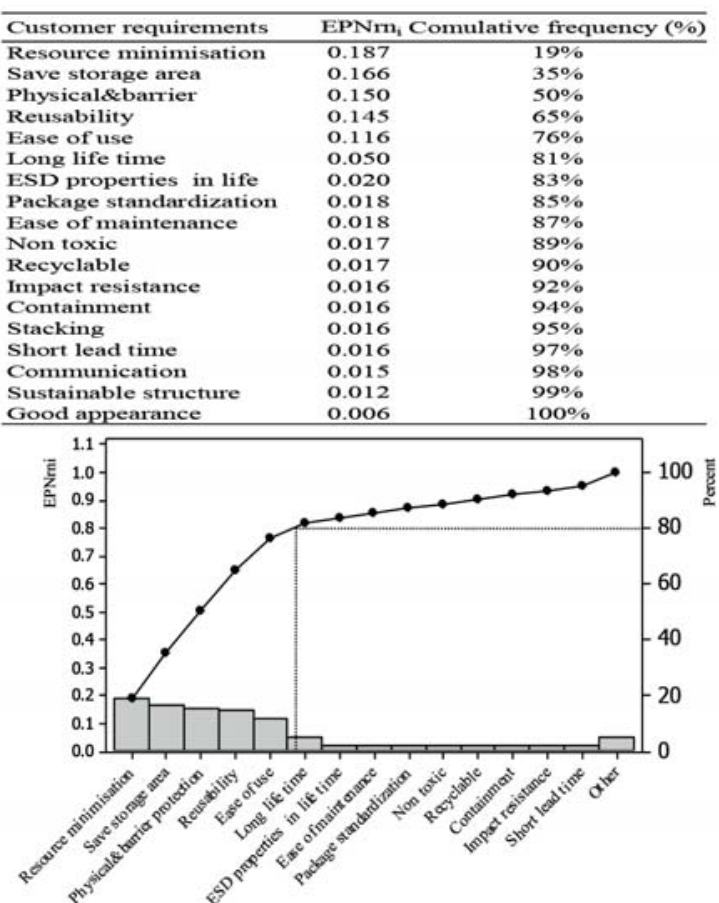

Figure 3: The critical priorities by Pareto 80:20.

Normalised Environmental Priority Number $\left(E P N r n_{i}\right)$ is calculated based upon equation (5) - (7).

Table 1: Environment priority number

\begin{tabular}{|c|c|c|c|c|c|c|c|c|}
\hline \multicolumn{2}{|c|}{ Customer requirement } & \multicolumn{7}{|c|}{ Prioritising } \\
\hline Life cycle phase & Spec Requirement & pi & $\begin{array}{l}\text { Company } \\
\text { impact (Ci) }\end{array}$ & $\begin{array}{c}\text { Market } \\
\text { impact (Mi) }\end{array}$ & $\begin{array}{c}\text { Environmental } \\
\text { impact (Ei) }\end{array}$ & ri & $\begin{array}{c}\text { EPN } \\
\text { ri }\end{array}$ & $\begin{array}{c}\text { EPN } \\
\text { rni }\end{array}$ \\
\hline \multirow{2}{*}{ Material Requistion } & ESD properties in life time & 0.05 & 3 & 4 & 2 & 24 & 1.20 & 0.020 \\
\hline & Sustainable structure & 0.06 & 3 & 2 & 2 & 12 & 0.72 & 0.012 \\
\hline & Resource minimisation & 0.09 & 5 & 5 & 5 & 125 & 11.25 & 0.187 \\
\hline$\checkmark$ & Short lead time & 0.04 & 4 & 3 & 2 & 24 & 0.96 & 0.016 \\
\hline \multirow{2}{*}{ Production } & Ease of maintenance & 0.04 & 3 & 3 & 3 & 27 & 1.08 & 0.018 \\
\hline & Good appearance & 0.03 & 3 & 4 & 1 & 12 & 0.36 & 0.006 \\
\hline & Package Standardization & 0.06 & 3 & 3 & 2 & 18 & 1.08 & 0.018 \\
\hline$\checkmark$ & Safe storage area & 0.08 & 5 & 5 & 5 & 125 & 10.00 & 0.166 \\
\hline \multirow{2}{*}{ Distribution } & Impact resistance & 0.04 & 4 & 3 & 2 & 24 & 0.96 & 0.016 \\
\hline & Stacking & 0.04 & 4 & 3 & 2 & 24 & 0.96 & 0.016 \\
\hline & Communication & 0.05 & 3 & 3 & 2 & 18 & 0.90 & 0.015 \\
\hline$\checkmark$ & Physical\&barrier Protection & 0.09 & 5 & 5 & 4 & 100 & 9.00 & 0.150 \\
\hline \multirow{2}{*}{ Usage } & Containment & 0.04 & 4 & 3 & 2 & 24 & 0.96 & 0.0 \\
\hline & Ease of use & 0.07 & 5 & 5 & 4 & 100 & 7.00 & 0.1 \\
\hline & Reusability & 0.07 & 5 & 5 & 5 & 125 & 8.75 & 0.1 \\
\hline$\checkmark$ & Long life time & 0.05 & 4 & 3 & 5 & 60 & 3.00 & 0.0 \\
\hline End of life & Non toxic & 0.05 & 2 & 2 & 5 & 20 & 1.00 & 0.017 \\
\hline & Recyclable & 0.05 & 2 & 2 & 5 & 20 & 1.00 & 0.017 \\
\hline
\end{tabular}

According to Table 1, it demonstrates the internal and external impacts of packaging requirements by using the Environmental Priority Number. The packaging requirements are prioritised by using score of Raw Normalised Environmental Priority Number $\left(E P N r n_{i}\right)$. Then, the requirements are systematised into a group of critical priorities by using the Pareto's rule 80:20 as illustrated in Figure 3. 


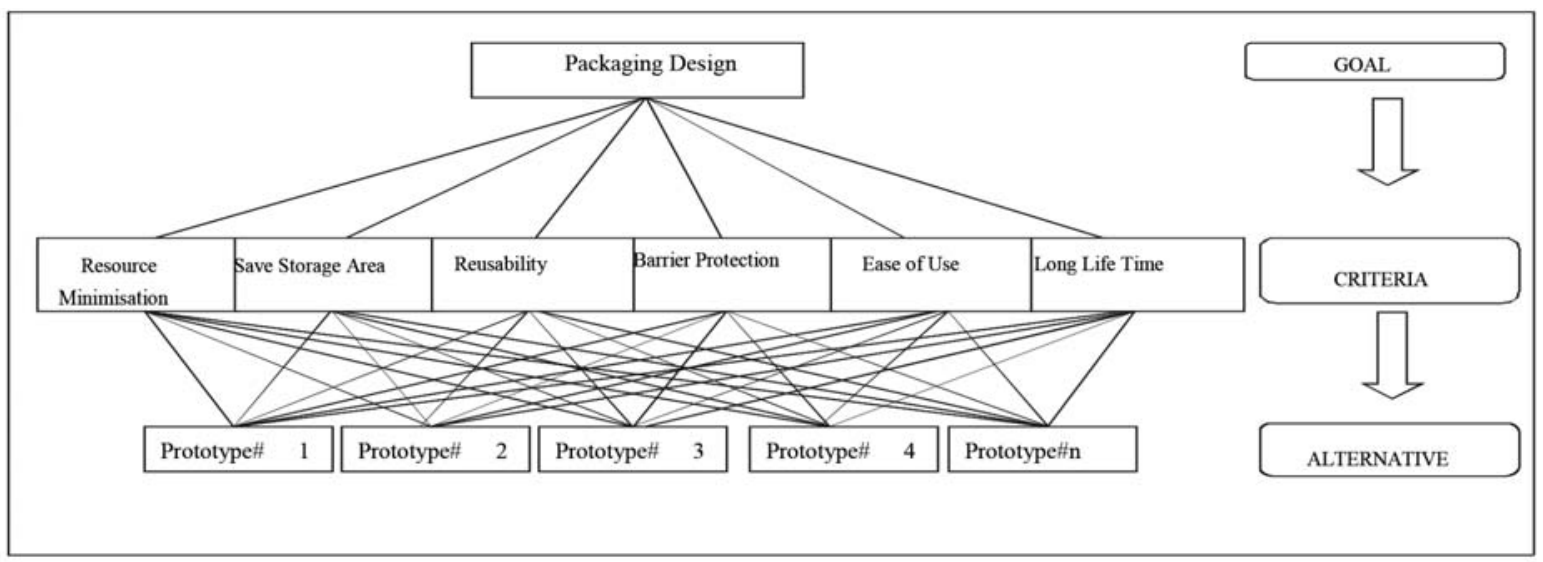

Figure 4: Packaging sustainable design hierarchy of HDD packaging case study.

Figure 3 illustrates that designers define the customer requirement criteria by using Pareto's rule $80: 20$. The critical criteria consist of six customer requirements; resource minimisation (score $=0.187$ ), save storage area (score $=0.166)$, physical\& barrier protection (score $=0.150)$, reusability $($ score $=0.145)$, ease of use (score $=0.116)$, and long lifetime $($ score $=$ $0.050)$.

\subsection{Functional definition}

This section, pro and con analysis and brainstorming amongst designers with major stakeholders to define the requirement's priorities by Analytic Hierarchy Process (AHP) can be applied as shown in Figure 4.

The stakeholders have several department experts team who employing with thirty persons. The production departments have fifteen persons, Process quality engineering departments have three persons, Packaging material suppliers have three persons, Process engineering departments have three persons, Environment safety health and security departments have four persons, and Customer satisfaction departments have two person. The stakeholders can include pair wise criteria in line with the aim of AHP at gaining relative weight from the stakeholder's viewpoint as illustrated in Table 2.

The result is illustrated in Table 2 showing that pair wise comparison is performed between critical criteria of hard disk drive packaging customer requirement for weighting factors. The importance weighting value $\left(W_{i}\right)$ is calculated as 0.414 for resource minimisation, 0.271 for save storage area, 0.031 for reusability, 0.157 for physical \& barrier protection, 0.079 for ease of use and 0.047 for long life time. The critical criteria of hard disk drive packaging customer requirements are scaled to nine rating scaling score.

Table 2: The criteria hierarchy of hard disk drive packaging case study

\begin{tabular}{|c|c|c|c|c|c|c|c|}
\hline Critical Criteria & $\begin{array}{c}\text { Resource } \\
\text { minimisation }\end{array}$ & $\begin{array}{c}\text { Safe storage } \\
\text { area }\end{array}$ & Reusability & $\begin{array}{c}\text { Physical\&barrier } \\
\text { protection }\end{array}$ & $\begin{array}{l}\text { Ease } \\
\text { of use li }\end{array}$ & $\begin{array}{l}\text { Long } \\
\text { life time }\end{array}$ & Wi \\
\hline Resource minimisation & 1 & 3 & 9 & 4 & 5 & 6 & 0.414 \\
\hline Safe storage area & $1 / 3$ & 1 & 9 & 3 & 5 & 6 & 0.271 \\
\hline Reusability & $1 / 9$ & $1 / 9$ & 1 & $1 / 4$ & $1 / 3$ & $1 / 2$ & 0.031 \\
\hline $\begin{array}{l}\text { Physical\&barrier } \\
\text { protection }\end{array}$ & $1 / 4$ & $1 / 3$ & 4 & 1 & 5 & 4 & 0.157 \\
\hline Ease of use & $1 / 5$ & $1 / 5$ & 3 & $1 / 5$ & 1 & 3 & 0.079 \\
\hline Long life time & $1 / 6$ & $1 / 6$ & 2 & $1 / 4$ & $1 / 3$ & 1 & 0.047 \\
\hline$\lambda \max =6.479$ & & C.I. $=0.092$ & R.I. $=1.320$ & C.R. $=$ & $0.073<0$ & & \\
\hline
\end{tabular}

\subsection{Concept making}

After packaging designers understand the majoring stakeholder's requirements and set the critical criteria for new design packaging development based upon importance weighting values $\left(W_{i}\right)$ following AHP methodology. The several alternatives should be developed with drawing or prototype forming. In this case study, the new hard disk drive packaging prototypes are developed into two options. The detail of design alternatives is shown in Appendix C Table C1.

Table 3 - 4 illustrates a single attribute utility function and trade-off analysis between a pair of attributes. The Multi-Attribute Utility Theory (MAUT) of hard disk drive packaging case study between current and new design packaging are presented. 
Table 3: Multi-Attribute Utility Theory (MAUT)

\begin{tabular}{|c|c|c|c|c|c|c|c|c|}
\hline \multirow{3}{*}{ Criteria } & \multirow{3}{*}{ Attribute } & \multirow{3}{*}{ Wi } & \multicolumn{6}{|c|}{ Packaging Type } \\
\hline & & & \multicolumn{2}{|c|}{$\begin{array}{c}\text { Current } \\
\text { packaging } \\
(A)\end{array}$} & \multicolumn{2}{|c|}{$\begin{array}{c}\text { New design } \\
\text { packaging } \\
(B)\end{array}$} & \multicolumn{2}{|c|}{$\begin{array}{c}\text { New design } \\
\text { Packaging } \\
(C) \\
\end{array}$} \\
\hline & & & $\underline{\underline{U}}_{\mathrm{i}}$ & $\mathrm{U}_{\mathrm{i}}^{-}$ & $\underline{\mathrm{U}}_{\mathrm{i}}$ & $\mathrm{U}_{\mathrm{i}}^{-}$ & $\underline{\mathrm{U}}_{\mathrm{i}}$ & $\mathrm{U}_{\mathrm{i}}^{-}$ \\
\hline Resource minimisation & Material weight (kg/pcs) & 0.414 & 0 & 0 & 0 & 1 & 1 & 1 \\
\hline Save storage area & Footprint Area ( $\left.\mathrm{ft}^{3 / p c s}\right)$ & 0.271 & 0 & 0 & 0 & 1 & 1 & 1 \\
\hline Reusability & Puncture strength $\left(\mathrm{kgf} / \mathrm{m}^{2}\right)$ & 0.031 & 0 & 1 & 0 & 0 & 1 & 1 \\
\hline Physical\&barrier protection & Impact resistance $(\mathrm{kgf} / \mathrm{pcs})$ & 0.157 & 1 & 1 & 0 & 0 & 0 & 1 \\
\hline Ease of use & Assembly Time (s/pcs) & 0.079 & 0 & 0 & 1 & 1 & 0 & 1 \\
\hline \multirow[t]{3}{*}{ Long life time } & Life time (month) & 0.047 & 1 & 1 & 0 & 1 & 0 & 0 \\
\hline & & & $\underline{\mathrm{B}}_{\mathrm{a}}$ & $\mathrm{B}_{\mathrm{a}}^{-}$ & $\underline{\mathrm{B}}_{\mathrm{b}}$ & $\overline{B_{b}}$ & $\underline{B}_{c}$ & $\mathrm{~B}_{\mathrm{c}}$ \\
\hline & Functional Utility (FU) & & 0.204 & 0.235 & 0.079 & 0.811 & 0.716 & 0.952 \\
\hline
\end{tabular}

From Table 3, the lower bound value new design packaging $(C)$ is higher than upper bound value of current packaging (A) $\left[\underline{B}_{C}=0.716>\overline{B^{A}}=0.235\right]$, then current packaging $(A)$ is rejected of boundary comparison. Thus, the mostly importance weighting value $\left(W_{i}\right)$ is calculated in adjusted boundary. The adjusted function value is illustrated in Table 4 .

Table 4: Recalculating Multi-Attribute Utility Theory

\begin{tabular}{|c|c|c|c|c|c|c|c|c|}
\hline \multirow{3}{*}{ Criteria } & \multirow{3}{*}{ Attribute } & \multirow[t]{3}{*}{ ary } & \multicolumn{6}{|c|}{ Packaging Type } \\
\hline & & & \multicolumn{2}{|c|}{$\begin{array}{c}\text { Current } \\
\text { packaging } \\
(A)\end{array}$} & \multicolumn{2}{|c|}{$\begin{array}{c}\text { New design } \\
\text { packaging } \\
(B)\end{array}$} & \multicolumn{2}{|c|}{$\begin{array}{c}\text { New design } \\
\text { Packaging } \\
(C)\end{array}$} \\
\hline & & & $\underline{\mathrm{U}}_{\mathrm{i}}$ & $\mathrm{U}_{\mathrm{i}}^{-}$ & $\underline{\mathrm{U}}_{\mathrm{i}}$ & $\mathrm{U}_{\mathrm{i}}^{-}$ & $\underline{\mathrm{U}}_{\mathrm{i}}$ & $\mathrm{U}_{\mathrm{i}}^{-}$ \\
\hline Resource minimisation & Material weight $(\mathrm{kg} / \mathrm{pcs})$ & 0.414 & 0 & 0 & 0.414 & 0.414 & 1 & 1 \\
\hline Save storage area & Footprint Area $\left(\mathrm{ft}^{3} / \mathrm{pcs}\right)$ & 0.271 & 0 & 0 & 0 & 1 & 1 & 1 \\
\hline Reusability & Puncture strength $\left(\mathrm{kgf} / \mathrm{m}^{2}\right)$ & 0.031 & 0 & 1 & 0 & 0 & 1 & 1 \\
\hline Physical\&barrier protection & Impact resistance (kgf/pcs) & 0.157 & 1 & 1 & 0 & 0 & 0 & 1 \\
\hline Ease of use & Assembly Time (s/pcs) & 0.079 & 0 & 0 & 1 & 1 & 0 & 1 \\
\hline \multirow[t]{2}{*}{ Long life time } & Life time (month) & 0.047 & 1 & 1 & 0 & 1 & 0 & 0 \\
\hline & Functional Utility (FU) & & $\begin{array}{c}\underline{B}_{\mathrm{a}} \\
0.204\end{array}$ & $\begin{array}{c}\mathrm{B}_{\mathrm{a}}^{-} \\
0.235\end{array}$ & $\begin{array}{c}\underline{B}_{b} \\
0.250\end{array}$ & $\begin{array}{c}\mathrm{B}_{\mathrm{b}} \\
0.568\end{array}$ & $\begin{array}{c}\underline{B}_{c} \\
0.716\end{array}$ & $\begin{array}{c}\mathrm{B}_{\mathrm{c}} \\
0.952\end{array}$ \\
\hline
\end{tabular}

\subsection{Packaging evaluation}

Finally, Value Engineering (VE) is presented in Table 5. The value engineering indexes are affected mostly on to optimum cost and function utility of packaging selection.

Table 5: Life cycle cost of internal factory packaging for hard disk drive industry

\begin{tabular}{lccc}
\hline \multicolumn{1}{c}{ Life cycle cost } & $\begin{array}{c}\text { Current } \\
\text { packaging }\end{array}$ & $\begin{array}{c}\text { New design } \\
\text { packaging }(\mathbf{B})\end{array}$ & $\begin{array}{c}\text { New design } \\
\text { Packaging }(\mathbf{C})\end{array}$ \\
\hline Material requisition $(\$ / p c s)$ & 0.504 & 0.167 & 0.391 \\
Manufacturing (\$/pcs) & 0.417 & 0.349 & 0.437 \\
Usage (\$/pcs) & 0.115 & 0.151 & 0.091 \\
Distribution $(\$ / p c s)$ & 0.075 & 0.103 & 0.068 \\
Disposal $(\$ / p c s)$ & 0.109 & 0.117 & 0.07 \\
\hline Total Life cycle cost(\$pcs) & 1.220 & 0.887 & 1.057 \\
\hline
\end{tabular}

Value in all life cycle stages as Equation (17);

$$
S P V_{B}\left\{\begin{array} { l } 
{ S P V _ { \underline { \underline { B } } } = \frac { 0 . 2 5 0 } { 0 . 8 8 7 } = 0 . 2 8 2 } \\
{ S P V _ { \overline { B } } = \frac { 0 . 5 6 8 } { 0 . 8 8 7 } = 0 . 6 4 0 }
\end{array} \quad S P V _ { C } \left\{\begin{array}{l}
S P V_{\underline{\underline{C}}}=\frac{0.716}{1.057}=0.677 \\
S P V_{\bar{C}}=\frac{0.952}{1.057}=0.901
\end{array}\right.\right.
$$

Lower value of new design packaging $(C)$ is higher than upper value of new design packaging (B) $\left[S P V_{\underline{C}}=0.677>S P V_{\bar{B}}=0.640\right]$, then new design packaging $(C)$ is optimised as eco packaging for internal factory hard disk drive industry. After using the decision support methodology, the packaging improvements in house factory packaging are developed for 2.5" and 3.5" Product implementation is illustrated in Table 6.

Table 6: Hard disk drive 2.5" and 3.5" product implements in case study

\begin{tabular}{|c|c|c|c|c|}
\hline \multirow{2}{*}{$\begin{array}{c}\text { Internal factory } \\
\text { packaging } \\
\text { attribute }\end{array}$} & \multicolumn{2}{|c|}{$\begin{array}{l}\text { Traditional } \\
\text { packaging }\end{array}$} & \multirow{2}{*}{$\begin{array}{c}\text { New design } \\
\text { packaging }\end{array}$} & \multirow{2}{*}{ Percent $(\%)$} \\
\hline & $2.5 " \mathrm{HDD}$ & 3.5"HDD & & \\
\hline Number of Parts (pcs) & 191 & 191 & 124 & $-35 \%$ (Based on 2.5" and 3.5" HDD) \\
\hline \multirow{2}{*}{$\begin{array}{l}\text { Unit footprint area } \\
\text { (ft/unit) }\end{array}$} & \multirow[t]{2}{*}{0.556} & \multirow[t]{2}{*}{0.7122} & \multirow[t]{2}{*}{0.284} & $-49 \%$ (Based on $2.5 " \mathrm{HDD})$ \\
\hline & & & & $-60 \%$ (Based on $3.5 " \mathrm{HDD})$ \\
\hline Working area $\left(\mathrm{ft}^{3}\right)$ & $1,114,864$ & $1,114,864$ & $1,038,065$ & $-67 \%$ (Based on 2.5" and 3.5" HDD) \\
\hline \multirow{2}{*}{ Unit cost (\$/unit) } & \multirow{2}{*}{25.53} & \multirow{2}{*}{31.72} & \multirow{2}{*}{13.04} & $-49 \%$ (Based on $2.5 " \mathrm{HDD}$ ) \\
\hline & & & & $-60 \%$ (Based on $3.5 " \mathrm{HDD}$ ) \\
\hline Total cost (S) & $3,308,602$ & $3,308,602$ & 136,098 & $-58 \%$ (Based on 2.5" and 3.5" HDD) \\
\hline \multirow{2}{*}{$\begin{array}{l}\text { Pallet packed size } \\
\text { (unit/pallet) }\end{array}$} & \multirow{2}{*}{48} & \multirow{2}{*}{40} & \multirow{2}{*}{120} & $+60 \%$ (Based on 2.5"HDD) \\
\hline & & & & $+67 \%$ (Based on $3.5 " \mathrm{HDD}$ ) \\
\hline
\end{tabular}

According to Table 6, the component parts can be reduced from current packaging based upon 2.5" and 3.5" HDD product around 35 percent. The unit footprint area can be reduced from current packaging by around 49 percent based upon 2.5" HDD product and around 60 percent based upon 3.5" HDD product. The working area can be reduced from current packaging based upon 2.5" and 3.5" HDD product around 67 percent. The unit cost can be reduced from current packaging by around 49 percent based upon 2.5" HDD product and around 60 percent based upon 3.5" HDD product. The total cost can be reduced from current packaging based upon 2.5" and 3.5" HDD product by around 58 percent. The pallet packed size can be increased from current packaging by around 60 percent based upon 2.5" HDD product and by around 67 percent based upon 3.5" HDD product. 
In summary, components of the packaging are identified, and analysed. Then the design changes have been made from the environmental perspective. From this study, a number of sustainable design strategies have been integrated into the redesign alternative such as: reduced number of parts, increased manufacturing capacity, and reduced production cost.

\section{Conclusions and Recommendations}

According to the evaluation process in the sustainable packaging design selection based upon life cycle thinking in ISO/TR 14062 is unavailable, the methodology for sustainable packaging design and process evaluation are presented in this paper. The objectives of this research are to develop the sustainable packaging methodology at the conceptual design phase, and to enhance the new guidelines to quantify efficient sustainable packaging evaluation process based upon ISO/TR 14062.

The contribution is highlighted into sustainable packaging design and life cycle evaluation by enhancing ISO/TR 14062 in a decision support methodology as illustrated in Figure 2. The packaging evaluation with a series of tool AHP, MAUT, VE are created to enhance the missing gap in ISO/TR 14062. The advantage of sustainable packaging approach and evaluation process then can be simplified with guidelines in the presented model. The designers and practitioners are provided with the new sustainable packaging design and evaluation ability for sustainable packaging prototype. The model in this research can enhance ISO/TR 14062 for the evaluation of sustainable design prototypes and sustainable packaging value and life cycle cost.

This methodology applies the integration of Quality Function Deployment for Environment (QFDE) within Environment Priority Number (EPN), Analytic Hierarchy Process (AHP), Multi-Attribute Utility Approach (MAUT) and Value Engineering (VE). The sustainable packaging value can be achieved based upon functions, economics and environment consciousness in packaging stakeholders. The conclusions from applying this methodology are outlined below.

The consequence of approach in a hard disk drive case study presents that the cost of redesign and weight of material can be reduced. This cost and material handle effectiveness can be achieved based upon ISO/TR 14062. The designers can reduce development cost and difficulties in making a decision to redesign packaging in a number of alternative designs according to the conceptual packaging design guideline. The packaging design approach can be deployed into the strategic improvement using the Quality Function Deployment for Environment (QFDE) method, particularly at packaging input and output process perspectives. The quality of the packaging is deployed based upon stakeholder's requirements (supplier, Manufacturer, Distributor, User and Disposal) using the QFDE method and verifying the priority cause-effect by using Environment Priority Number (EPN) quantities. This approach has been tested according to internal impacts (company), external impacts (customer) and environmental and social impacts. An approach criterion for sustainable packaging are developed and ranked by the Analytic Hierarchy Process (AHP). This means the quantitative and qualitative criteria can be analysed in the methodology.

The main factors including manufacturability, assembly ability and environmental factors are combined during the Multi-Attribute Utility Theory (MAUT) process. The packaging designer can achieve the optimum cost and function utility of packaging selection by using Sustainable Packaging Value (EPV) in the life cycle cost thinking based upon ISO/TR 14062.

This paper has attempted to provide a systematic packaging design approach for sustainable packaging and evaluate the packaging by each process design systematically. The contribution of this research lies in the approach to consolidate and integrate function, economics, and environment consciousness in packaging stakeholders as a life cycle concept in ISO/TR 14062. An approach can be modified in other industries according to their specific quantitative and qualitative criteria, and achieving desirable function and minimising cost and environmental impact. This research has applied AHP in the functional definition so that the designer can prioritise the customer requirement criteria and can achieve consistency of comparisons between alternatives according to the judgments. Packaging designers can select the optimal sustainable packaging worth by applying VE by using ratio of function from MAUT and life cycle cost. The packaging evaluation can verify steps to obtain efficient decision-making. 
Limitations in applications are in the structure, which primarily depend upon the background knowledge of packaging design, and previous packaging databases, which are quite rare in industries. Packaging Specialist teamwork also plays an extremely important role in the whole development process. Another limitation is that the real figure of current and newly developed of internal factory packaging are classified due to a non disclosure agreement, therefore, the author cannot reveal to the public.

For further studies, additional design phase emphasize the product packing stage and usage stage such as product assembly, packaging lifetime usage and returnable packaging in reverse logistics can be applied. Moreover, detailed manufacturing design process improvements such as handling costs, supporting tool costs such as jig fixture, assembly cost, inventory cost, and distribution cost should be explored and applied to identify the sustainable packaging.

\section{Acknowledgements}

The authors would like to express sincere gratitude to Industry/University Cooperative Research Center (I/UCRC) in HDD Component, the Faculty of Engineering, Khon Kaen University and National Electronics and Computer Technology Center, National Science and Technology Development Agency (CPNHR-02-01-51 D). The authors are very appreciative to all the anonymous reviewers for their valuable comments. 


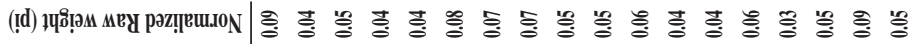

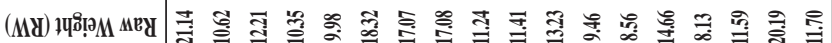

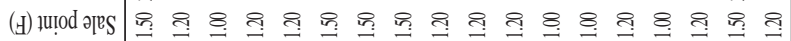

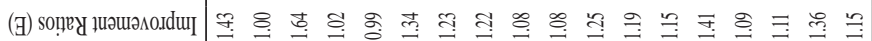
(๘)

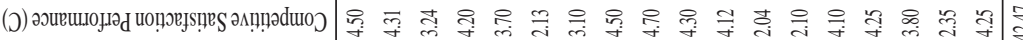

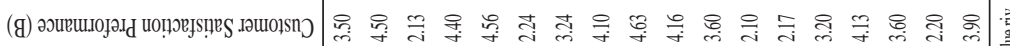

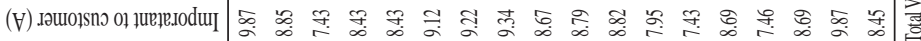

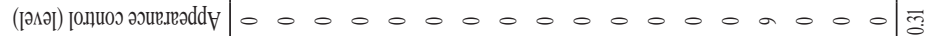

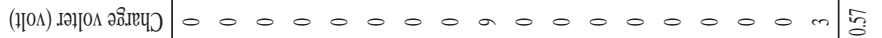

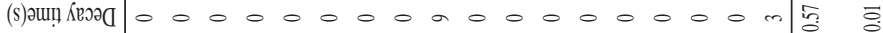

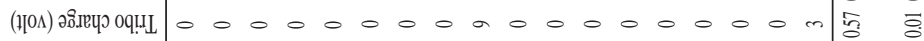

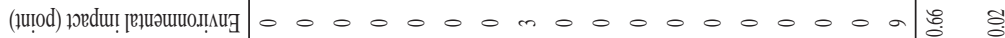

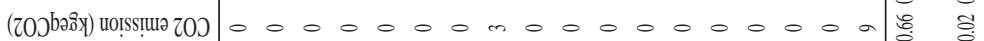

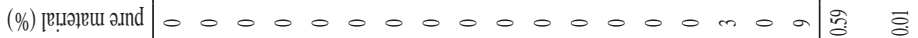

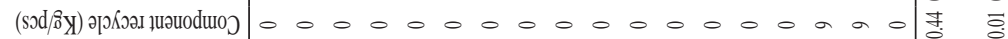

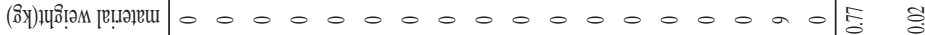

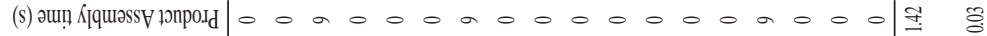

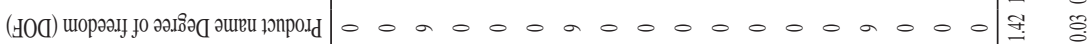

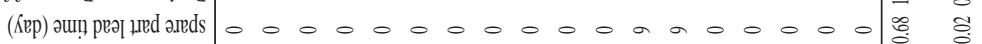

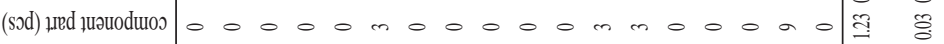




\section{Appendix B}

Table B1: Rating scale [12]

\begin{tabular}{|c|l|l|}
\hline $\begin{array}{c}\text { Intensity of } \\
\text { importance }\end{array}$ & \multicolumn{1}{|c|}{ Definition } & \multicolumn{1}{c|}{ Explanation } \\
\hline 1 & Equal importance & Two factors contribute equally to the objective. \\
\hline 3 & Somewhat more important & Experience and judgement slightly favour one over the other. \\
\hline 5 & Much more important & Experience and judgement strongly favour one over the other. \\
\hline 7 & Very much more important & $\begin{array}{l}\text { Experience and judgement very strongly favour one over the other. Its importance } \\
\text { is demonstrated in practice. }\end{array}$ \\
\hline 9 & Absolutely more important & The evidence favouring one over the other is of the highest possible validity. \\
\hline $2,4,6,8$ & Intermediate values & When compromise is needed. \\
\hline
\end{tabular}

Table B2: Value of the Random Index $(R I)[12]$

\begin{tabular}{|c|c|c|c|c|c|c|c|c|c|}
\hline $\boldsymbol{n}$ & $\mathbf{2}$ & $\mathbf{3}$ & $\mathbf{4}$ & $\mathbf{5}$ & $\mathbf{6}$ & $\mathbf{7}$ & $\mathbf{8}$ & $\mathbf{9}$ & $\mathbf{1 0}$ \\
\hline $\boldsymbol{R I}$ & 0 & 0.58 & 0.90 & 1.12 & 1.24 & 1.32 & 1.41 & 1.45 & 1.51 \\
\hline
\end{tabular}

\section{Appendix C}

Table C1: Comparison packaging prototype by the Multi-Attribute

\begin{tabular}{|c|c|c|c|c|c|c|c|c|c|c|}
\hline \multirow[b]{3}{*}{ Criteria } & \multirow[b]{3}{*}{ Attribution } & \multirow{2}{*}{\multicolumn{3}{|c|}{$\begin{array}{c}\text { Traditional packaging } \\
(A)\end{array}$}} & \multicolumn{6}{|c|}{ Packaging Type } \\
\hline & & & & & \multicolumn{3}{|c|}{$\begin{array}{c}\text { New design packaging } \\
(B)\end{array}$} & \multicolumn{3}{|c|}{$\begin{array}{c}\text { New design Packaging } \\
(C)\end{array}$} \\
\hline & & $\begin{array}{l}\text { Rigid } \\
\text { wrapping } \\
\text { tray }\end{array}$ & $\begin{array}{l}\text { Partition } \\
\text { cross } \\
\text { section } \\
\text { slots }\end{array}$ & $\begin{array}{l}\text { Folding } \\
\text { handle } \\
\text { set }\end{array}$ & $\begin{array}{l}\text { Foldable } \\
\text { froming } \\
\text { tray }\end{array}$ & $\begin{array}{c}\text { Flexible } \\
\text { dimension } \\
\text { slots }\end{array}$ & $\begin{array}{l}\text { Plain } \\
\text { Plastic } \\
\text { handle }\end{array}$ & $\begin{array}{c}\text { Foldable } \\
\text { assembly } \\
\text { based } \\
\text { box }\end{array}$ & $\begin{array}{l}\text { Assemble } \\
\text { partition } \\
\text { parts }\end{array}$ & $\begin{array}{l}\text { Fitting } \\
\text { plastic } \\
\text { handle }\end{array}$ \\
\hline Resource minimisation & Material weight $(\mathrm{kg} / \mathrm{pcs})$ & \multicolumn{3}{|c|}{$0.87 \#$} & \multicolumn{3}{|c|}{1.22} & \multicolumn{3}{|c|}{$1.51 *$} \\
\hline Save storage area & Footprint Area $\left(\mathrm{ft}^{3} / \mathrm{pcs}\right)$ & \multicolumn{3}{|c|}{$0.722 \#$} & \multicolumn{3}{|c|}{0.658} & \multicolumn{3}{|c|}{$0.284^{*}$} \\
\hline Reusability & Puncture strength $\left(\mathrm{kg}_{\mathrm{f}} / \mathrm{m}^{2}\right)$ & \multicolumn{3}{|c|}{40.2} & \multicolumn{3}{|c|}{$37.4 \#$} & \multicolumn{3}{|c|}{$56.7^{*}$} \\
\hline $\begin{array}{l}\text { Physical \& barrier } \\
\text { protection }\end{array}$ & Impact resistance $\left(\mathrm{kg}_{\mathrm{f}} / \mathrm{pcs}\right)$ & \multicolumn{3}{|c|}{$0.926^{*}$} & \multicolumn{3}{|c|}{$0.715 \#$} & \multicolumn{3}{|c|}{0.715} \\
\hline Ease of use & Assembly Time (s/pcs) & \multicolumn{3}{|c|}{$3.55 \#$} & \multicolumn{3}{|c|}{$2.94 *$} & \multicolumn{3}{|c|}{3.21} \\
\hline Long life time & Life time (month) & \multicolumn{3}{|c|}{$12 *$} & \multicolumn{3}{|c|}{9} & \multicolumn{3}{|c|}{$8 \#$} \\
\hline
\end{tabular}




\section{Reference}

[1] M. Grayson, "Fuel and Resource Recovery," Economic and Environmental Factors, NewYork: John Wiley, 1984.

[2] K. D. Maria, The packaging development process, PA: Technomic, 2000.

[3] M. Charter and U. Tischer, Sustainable solutions, England: Greenleaf Publishing, 2001.

[4] H. Guiping and B. Bopaya, "Modelling sustainable product life cycle decision support system," International Journal of Production Economics, vol. 122, pp. 366-375, 2009.

[5] B. Fynes and D. S. Burca, "The effects of design quality on quality performance," International Journal of Production Economics, vol. 96, pp. 1-14, 2005.

[6] ISO/TR14062 (2002). Environmental Management- Integrating Environmental Aspects into Product Design and Development. [Online]. Available: http://www.iso.org/iso

[7] S. Kees, J. Karli James, F. Leanne, and L.Helen, "Sustainable Packaging: How do We Define and Measure It," IAPRI Symposium, 2005, pp. 1-9.

[8] T. Sakao, "QFD-Centred Design Methodology for Environmentally Conscious Product Design," International Journal of Production Research, vol. 45, pp. 4143-4162, 2007.
[9] H. Kobayashi, “A systematic approach to eco- innovative packaging design based upon life cycle planning," Advanced Engineering Informatics, vol. 20, pp. 113-125, 2006.

[10] B. Y. Sheng and L. C. Jahau, "An Eco- Innovative Tool by Integrating FMEA and TRIZ Method," IEEE, pp. 678-683, 2005.

[11] L.C. Jaha and K.C. Wai, "Matrix-Type and Pattern-Based Simple LCA for Eco-Innovative Design of Packaging," IEEE, pp. 467-472, 2003.

[12] T. L. Saaty, The Analytical Hierarchy Process, New York: McGraw-Hill, 1980.

[13] M. T. Tabucanon, Multiple Criteria Decision Making in Industry, Amsterdam: Elsevier Science Publishing Company Inc, 1988.

[14] S. L. Chan and W. H. Ip, "A dynamic decision support system to predict the value of customer for new product development," Decision Support Systems, vol. 52, pp. 178-188, 2011.

[15] S. K. Yu, B. Liu, W. Hua, and W. D. Zhou, "Contact-induced off-track vibrations of air bearing slider suspension system in hard disk drives," Tribology Letters, vol. 21, pp. 27-36, 2008.

[16] Q. Z. Yang and B. Song, "Eco-Design for Packaging Lifecycle Sustainability," IEEE International conference on industrial informatics, pp. 548-553, 2006. 